\title{
Prevalence of Metabolic Syndrome in Young Patients with ST-Elevation Myocardial Infarction
}

Dear Editor,

I read with interest the outstanding study by $\mathrm{Oz}$ et al.$^{[1]}$ on the prevalence of metabolic syndrome (MS) in Turkish young patients with ST-elevation myocardial infarction (STEMI). On employing the National Cholesterol Education Program Adult Treatment Panel III (NCEP-ATP III criteria), the authors found a high prevalence of MS (46.8\%), and the most frequent component of MS was low high-density lipoprotein level $(84.8 \%)$ followed by elevated triglycerides $(78.1 \%){ }^{[1]}$ I presume that these results ought to be cautiously interpreted. Apart from many limitations addressed by the authors, namely single-center study, not searching to examine the long-term clinical outcomes of all the studied patients, and lack of detailed assessment of vessels lesions, I presume that the following methodological limitation might be further relevant. This limitation is related to the MS definition criteria employed in the study. The impact of this limitation could be addressed in two aspects. On the one hand, there are many definition criteria for MS in the clinical setting and researches. These include the following: NCEP-ATP III; the International Diabetes Federation (IDF); the American Heart Association (AHA), and the World Health Organization (WHO). There is a global confusion on the precision of these criteria to diagnose MS. For instance, in a Turkish study, comparing the prevalence of MS among obese children and adolescents using WHO and NCEP-ATP III guidelines showed that $24 \%$ of the subjects were diagnosed as MS according to the NCEP while $38.8 \%$ were diagnosed according to the WHO-defined MS. The study recommended using WHO guidelines in the diagnosis of MS as this might detect more patients with MS and lead to better monitoring of them and prevention of their future sequelae. ${ }^{[2]}$ In another Italian study, evaluation of three criteria, namely NCEP-ATP III, IDF, and AHA, showed that the prevalence of MS was significantly estimated higher on employing the AHA and IDF as compared to the ATP III definition and that AHA and IDF definitions were found more sensitive than that of ATP III in diagnosing MS. ${ }^{[3]}$ On the other hand, the ATP III criteria employed in Oz et al.'s study ${ }^{[1]}$ are old and are no more worthy as they were set nearly a decade ago. ${ }^{[4]}$ As many national associations have proposed their own diagnostic MS criteria, ${ }^{[5]}$ I presume that constructing national Turkish MS definition criteria could better determine the prevalence of MS in patients with various health disorders. Despite the above-mentioned limitations, the study results urge the need for strict actions to reduce the future risk of cardiovascular consequences in patients with STEMI.

\section{Financial support and sponsorship}

Nil.
Conflicts of interest

There are no conflicts of interest.

Mahmood Dhahir Al-Mendalawi

Department of Paediatrics, Al-Kindy College of Medicine, University of Baghdad, Baghdad, Iraq

ORCID:

Mahmood Dhahir Al-Mendalawi: https://orcid.org/0000-0003-2872-453X

Address for correspondence: Prof. Mahmood Dhahir Al-Mendalawi, P.0. Box 55302, Baghdad Post Office, Baghdad, Iraq.

E-mail: mdalmendalawi@yahoo.com

\section{RefEREnCES}

1. Oz TK, Özbilgin N, Sungur A, Bas EG, Zengin A, Gürol T, et al. Prevalence of metabolic syndrome in young patients with ST-elevation myocardial infarction. Int J Cardiovasc Acad 2018;4:53-8.

2. Cizmecioğlu FM, Hatun S, Kalaça S. Metabolic syndrome in obese Turkish children and adolescents: Comparison of two diagnostic models. Turk J Pediatr 2008;50:359-65.

3. Mancia G, Bombelli M, Facchetti R, Casati A, Ronchi I, Quarti-Trevano F, et al. Impact of different definitions of the metabolic syndrome on the prevalence of organ damage, cardiometabolic risk and cardiovascular events. J Hypertens 2010;28:999-1006.

4. Expert Panel on Detection, Evaluation, and Treatment of High Blood Cholesterol in Adults. Executive summary of the third report of the National Cholesterol Education Program (NCEP) expert panel on detection, evaluation, and treatment of high blood cholesterol in adults (Adult Treatment Panel III). JAMA 2001;285:2486-97.

5. Xing Y, Xu S, Jia A, Cai J, Zhao M, Guo J, et al. Recommendations for revision of Chinese diagnostic criteria for metabolic syndrome: A nationwide study. J Diabetes 2018;10:232-9.

This is an open access journal, and articles are distributed under the terms of the Creative Commons Attribution-NonCommercial-ShareAlike 4.0 License, which allows others to remix, tweak, and build upon the work non-commercially, as long as appropriate credit is given and the new creations are licensed under the identical terms.

Submission: 13-Aug-18 Accepted: 04-Sep-18

\begin{tabular}{|l|l|}
\hline \multicolumn{2}{|c|}{ Access this article online } \\
\hline Quick Response Code: & Website: \\
\hline & www.ijcva.com \\
\hline & \\
\hline
\end{tabular}

How to cite this article: Al-Mendalawi MD. Prevalence of metabolic syndrome in young patients with ST-elevation myocardial infarction. Int $\mathrm{J}$ Cardiovasc Acad 2019;5:35.

(c) 2019 International Journal of the Cardiovascular Academy | Published by Wolters Kluwer Medknow 